\title{
COMPARANDO BANCOS DE DADOS DE FREQÜÊNCIAS ALÉLICAS DO BRASIL E DOS ESTADOS UNIDOS BASEADOS EM MARCADORES STR
}

\author{
Comparing Brazilian And North American Allelic Frequencies \\ Databases According To STR Markers
}

Grazielly Alves de Almeida Vaz',2

Daniela de Melo e Silva ${ }^{3}$

\begin{abstract}
Resumo
Neste trabalho foram comparadas as freqüências alélicas de 10 marcadores STR (CSF1PO, FGA, TPOx, vWA, D5S818, D3S1358, D8S1179, D13S317, D21S11 e TH01) nas populações brasileira e norte-americana. Tais freqüências foram obtidas a partir de 02 artigos científicos que descreverem os valores encontrados para cada grupo. Em um dos trabalhos foram analisados 794 indivíduos saudáveis provenientes em sua maioria das regiões central, sudoeste e sul do Brasil e em uma menor proporção, indivíduos das regiões norte e nordeste. Esses indivíduos constituíram uma amostra representativa da miscigenação racial tão típica do país. No outro trabalho, referente à população norte-americana, foram analisados 302 indivíduos saudáveis de origem caucasiana, 258 de origem afro-americana e 140 de origem hispânica. As freqüências alélicas das duas populações foram plotadas em tabelas e comparadas com a utilização do teste t de Student. Desta forma, o objetivo deste estudo foi comparar dados de freqüências alélicas em loci STR, das populações brasileira e norte-americana. Contudo, não foram verificadas diferenças estatisticamente significativas, ( $p>0,005)$, entre as freqüências alélicas dos 10 marcadores STR utilizados em exames de vínculo genético, indicando a possibilidade de se utilizar bancos de dados norte-americanos, em análises de DNA de populações brasileiras.
\end{abstract}

Palavras-chave: Freqüências alélicas; Populações brasileira e norte-americana; Marcadores STR.

\footnotetext{
Enviar correspondência para: Grazielly Alves de Almeida Vaz, Av. T-7 n. 100 Apt. 102, Ed. Pablo Picasso, Setor Oeste. CEP: 74140-110, Goiânia-Goiás. e-mail: graziellyvaz@hotmail.com

2 Discente do Programa de Especialização em Genética, Universidade Católica de Goiás, Goiânia-Goiás.

3 Docente do Programa de Especialização em Genética, Universidade Católica de Goiás, Goiânia-Goiás; Núcleo de Pesquisas Replicon, Departamento de Biologia, Universidade Católica de Goiás, Goiânia-Goiás.
} 


\section{Abstract}

We compared allelic frequencies of 10 STR markers (CSF1PO, FGA, TPOx, vWA, D5S818, D3S1358, D8S1179, D13S317, D21S11 e TH01) from Brazil and United States of America (USA). Such allelic frequencies were obtained of two papers that described the values found by the two groups. In one paper, the authors analyzed 794 healthy individuals from central, southeast and south regions of Brazil, and in less proportion, individuals from north and northeast regions. Such individuals constituted a representative sample of racial admixture of Brazil. In the other paper, in USA, the authors analyzed 302 healthy caucasoids, 258 africanamericans and 140 hispanics. The allelic frequencies of the two populations were plotted in tables and were compared, according to Student t-test. In this way, the aim of this study was to compare allelic frequencies data in STR loci, of Brazilians and Americans. However, no statistical significant differences were found in the allelic frequencies of these groups ( $p>0.005$ ), indicating the possibility of using American frequencies in analyses of forensics and paternity of individuals from Brazil.

Keywords: Allelic frequencies; Brazil and USA populations; STR markers.

\section{Introdução}

Nos últimos tempos, tem havido um grande aumento na quantidade de informações sobre variabilidade genética das populações devido à crescente preocupação com a diminuição da biodiversidade (1). Questões e tópicos como este são objeto de estudo da genética de populações, ou seja, o ramo da genética que visa a investigação das leis que governam a estrutura genética das populações naturais e buscam a elucidação dos mecanismos que a alteram, por meio de modelos ou representações simplificadas da realidade (2). A Genética de Populações procura compreender e fazer previsões dos efeitos de fenômenos genéticos como a segregação, recombinação, transposição e mutação sobre as populações, tendo em conta fatores ecológicos e evolucionários como a dimensão da população, padrões de reprodução, distribuição geográfica de indivíduos, migração e seleção (3). As questões freqüentemente abordadas em genética populacional incluem a amplitude da variação genética encontrada nas populações naturais, os processos evolutivos que moldam a estrutura genética das populações, os processos responsáveis pelo surgimento de divergência genética, a influência das características biológicas, tais como o tipo de reprodução, a fecundidade e a estrutura etária, sobre o pool genético das populações (3). A Genética de Populações nasceu por volta de 1903 com a publicação por Castle de um artigo no qual tal pesquisador desenvolvia um princípio simples, que relacionava, em uma população ideal constituída por indivíduos com reprodução sexuada que se acasalam ao acaso, as freqüências genotípicas (4). Esse princípio, no entanto, foi designado como Lei de Hardy-Weinberg (5).

A Genética de Populações, como pode ser visto em Castilho (3), ainda contou com as contribuições dos trabalhos de Fisher (1918), Wright (1921) e Haldane (1932). De fato, como ainda relata esta autora, esses cientistas consideraram muitos dos problemas fundamentais da Genética de Populações e só mais recentemente, com a descoberta de grande quantidade de variabilidade genética, revelada pela eletroforese, surgiram novas áreas de experimentação e teorização. A equação que se tornou o ponto fundamental de todo o desenvolvimento da genética de populações é conhecida mundialmente como "lei do equilíbrio de Hardy e Weinberg", e demonstra matematicamente que as freqüências gênicas de uma determinada população não se alterarão e as proporções genotípicas atingirão um equilỉbrio estável, mostrando uma relação constante ao longo do tempo, em uma população que obedeça às seguintes premissas, como descritas por Beiguelman (2):

a população é infinitamente grande; existe o mesmo número de homens e de mulheres na população; a população está em panmixia, isto é, os casamentos ocorrem ao acaso, não existindo, por conseguinte, estratificação social, casamentos preferenciais entre indivíduos com o mesmo genótipo, casamentos consangüíneos; todos os casais da população são igualmente férteis e geram o mesmo número de filhos; não há sobreposição de gerações na população, isto é, elas não se cruzam ao longo do tempo, porque todos os indivíduos devem ter a mesma idade ao casar; não há miscigenação da população original com outra imigrante, que apresente freqüências gênicas diferentes, nem emigração diferencial, isto é, a saída de grupos de indivíduos com freqüências gênicas distintas do resto da população. Em outras palavras, a população não recebe, nem emite um fluxo gênico capaz de alterar a sua composição genética inicial; os genes da população 
não sofrem mutação; e ninguém na população está sob pressão seletiva, pois todos os indivíduos são igualmente viáveis, não existindo fatores que aumentem ou diminuam a sobrevivência de indivíduos com determinado genótipo. Ainda de acordo com Beiguelman (2), se uma população humana obedecesse às premissas descritas, apresentaria estabilidade genética e permaneceria inalterada através dos tempos, ou seja, as populações humanas mostrariam uma fixidez genética ou inércia evolutiva, pois não estariam sujeitas aos fatores evolutivos como: mutação, seleção, fluxo gênico e deriva genética.

Um dos principais fatores evolutivos, a mutação, é um processo importante em genética de populações, constituindo a fonte de variação genética (6). A mutação pode envolver somente uma base de DNA, várias bases, parte do cromossomo ou de vários cromossomos. Em genética de populações interessam, sobretudo, as mutações espontâneas (4). Segundo Castilho (3), fluxo gênico, também conhecido por migração, corresponde ao movimento de indivíduos entre populações. A migração pode afetar as frequências alélicas das populações envolvidas, se existirem diferenças entre as frequências alélicas dos indivíduos que migram e a população que os recebe. Se houver um grande número de migradores entre as duas populações, o efeito será o de integrar as duas populações numa única população panmítica. O outro extremo será o isolamento completo das subpopulações, em que haverá menos variação intrapopulacional, mas grande divergência interpopulacional. A seleção é a preservação das variações favoráveis e a eliminação das variações deletérias de uma determinada espécie. Ela é baseada no fato de que as espécies têm mais descendentes do que aqueles que podem sobreviver e reproduzir-se; e que diferentes organismos têm capacidades distintas de sobreviver e reproduzir; e ainda que parte da variação na capacidade de sobrevivência e reprodução é hereditária. Este fator evolutivo pode ocorrer de vários modos afetando a fertilidade ou o sucesso reprodutivo de uma espécie (2). O termo deriva genética é o nome dado à flutuação puramente randômica nas freqüências alélicas de uma população ao longo do tempo, devido a um efeito de amostragem, considerando que o conjunto de genes de uma geração não é simplesmente uma cópia exata da geração precedente, mas sim uma pequena amostra (7).

Ainda de acordo com Pena (7), o norteamericano Sewall Wright (1889-1988), um dos pais da genética de populações e da síntese evolucionária moderna, foi o primeiro a chamar a atenção para a deriva genética. Sewal Wright verificou que, quando o tamanho efetivo da população é pequeno, como no caso das tribos indígenas e isolados genéticos ou diminui muito por epidemias ou guerra, podem ser observadas variações importantes nas freqüências alélicas de uma geração para outra por causa da deriva genética, o que é conhecido como efeito gargalo. Um caso extremo desse fenômeno, chamado "efeito fundador", ocorre quando um pequeno grupo de pessoas migra para um local e cria uma nova população. Se algum alelo por acaso ocorrer em alta freqüência na população "fundadora", ele ficará superrepresentado na população "filha" (2).

Um outro termo muito empregado em genética de populações, sendo utilizado para inferir os processos evolutivos citados anteriormente e que moldam a estrutura genética populacional é intitulado marcador molecular. Tal denominação constitui qualquer padrão oriundo de segmentos codificáveis ou não do DNA. Se a herança do marcador ocorre segundo os princípios de segregação mendeliana, este é considerado como um marcador genético (8). Dentre as principais classes de marcadores, podem ser destacados as aloenzimas, os polimorfismos de comprimento de fragmento de restrição (RFLP), os polimorfismos de DNA amplificados ao acaso (RAPD), os polimorfismos de nucleotídeo único (SNP) e os microssatélites e minissatélites, que se baseiam em seqüências de DNA repetitivo [Ferreira e Grattapaglia, 1995 apud Talhari (9)]. Neste estudo serão detalhados os marcadores do tipo microssatélites também conhecidos como STR (do inglês, Short Tandem Repeat).

De acordo com Jobse [1995 apud Talhari (9)], a maioria dos genomas eucariotos e parte dos procariotos são caracterizados pela presença de seqüências simples de DNA repetitivo distribuídas ao longo do genoma e classificadas de acordo com o número de nucleotídeos e sua complexidade. Os marcadores STR consistem em regiões de repetições seqüenciais distribuídas por todo o genoma humano, curtas, num número que pode variar de 1 a 7 bases de comprimento $(9,10,11)$. Estas regiões são uma rica fonte de marcadores altamente polimórficos e desta forma possuem um potencial quase ilimitado para que mais locos sejam descobertos e validados para uso forense (12). Seus alelos podem ser diferenciados pelo número de cópias da seqüência repetitiva contida na região analisada (13). 
A principal técnica utilizada para a análise dos STR é a Reação em Cadeia da Polimerase (PCR), que amplifica a seqüência estudada por vários ciclos térmicos, podendo diferenciar alelos pela fluorescência, e separá-los pela eletroforese (14). A genotipagem com STR é a técnica mais eficiente para analisar pouca quantidade de DNA ou DNA degradado. A realização da técnica é relativamente simples, rápida e de fácil padronização. Os locos de STRs apresentam alta taxa de mutação, tamanhos pequenos e definidos dos fragmentos permitem múltiplas amplificações simultâneas (multiplex), sem a necessidade do uso da radioatividade (15). O uso consagrado de marcadores moleculares se deve aos seus altos níveis de diversidade, baixas taxas de mutação e simplicidade da técnica, e ainda gerou um aumento na publicação de dados sobre sequenciamentos e freqüências alélicas populacionais (16). Além de apresentarem aplicações na caracterização populacional, os marcadores moleculares podem ainda ser utilizados em estudos de ligação, construção de mapas genéticos e investigação de parentesco, diagnóstico de doenças, genética populacional e melhoramento genético [Barendse et al., 1997 e Pepin et al., 1995 apud Talhari, (9)]. Outra vantagem da utilização dos marcadores moleculares é que os perfis alélicos podem ser gravados no computador em formatos digitais, permitindo a comparação direta com bancos de dados de freqüências alélicas da população local (17). Estes bancos de dados auxiliam no conhecimento de um determinado perfil de DNA sem a necessidade de testar toda a população, por meio da estimativa da freqüência desse perfil (18). As freqüências são calculadas a partir de um banco de dados de referência, provindos de diversas fontes, tais como, bancos de sangue, laboratórios que realizam testes de paternidade, pessoas que trabalham no laboratório, clientes de centros de aconselhamento genéticos, funcionários ligados à polícia e pessoas acusadas de crimes (18).

Desta forma, o objetivo deste estudo foi comparar dados de freqüências alélicas em loci STR, das populações brasileira e norte-americana. Para isso foi realizada uma meta-análise de dados de freqüências alélicas publicados em dois artigos científicos $(19,20)$. A finalidade desta análise foi conhecer a estrutura genética dessas populações e inferir os fatores evolutivos que atuam na formação das duas populações. Além disso, foram verificadas possíveis diferenças entre as freqüências alélicas de 10 marcadores STR, utilizados em exames de vínculo genético, averiguando a necessidade da construção de bancos de dados de freqüências alélicas locais, baseados em marcadores STR.

\section{Material e Métodos}

\section{Grupo amostral}

Foram avaliados indivíduos das populações brasileira e norte-americana. Da população brasileira, foram analisados 794 indivíduos saudáveis provenientes em sua maioria das regiões central, sudoeste e sul do Brasil e em uma menor proporção, indivíduos das regiões norte e nordeste. Esses indivíduos constituíram uma amostra representativa da miscigenação racial tão típica do país. Da população norteamericana foram analisados 302 indivíduos saudáveis de origem caucasiana, 258 de origem afro-americana e 140 de origem hispânica.

\section{Marcadores selecionados}

Foram analisadas as freqüências alélicas de 10 marcadores STR, a seguir CSF1PO, FGA, TPOx, vWA, D5S818, D3S1358, D8S1179, D13S317, D21S11 e TH01 nas populações brasileira e norte-americana.

\section{Análises estatísticas das freqüências alélicas}

Os dados das freqüências alélicas, das populações brasileira e norte-americana, foram plotados em tabelas e comparados pelo teste t de Student, com a utilização do software Biestat 3.0 (21).

\section{Resultados}

As freqüências alélicas observadas para os marcadores CSF1PO, FGA, TPOx, vWA, D5S818, D3S1358, D8S1179, D13S317, D21S11 e TH01 nas populações brasileira e norte-americana estão descritas na tabela 1 , assim como os valores de p obtidos nos resultados das análises dos testes t. Como pode ser observado na tabela 1 , não houve diferenças estatisticamente significativas ( $p>0,005)$ entre as freqüências alélicas dos dez marcadores selecionados. 


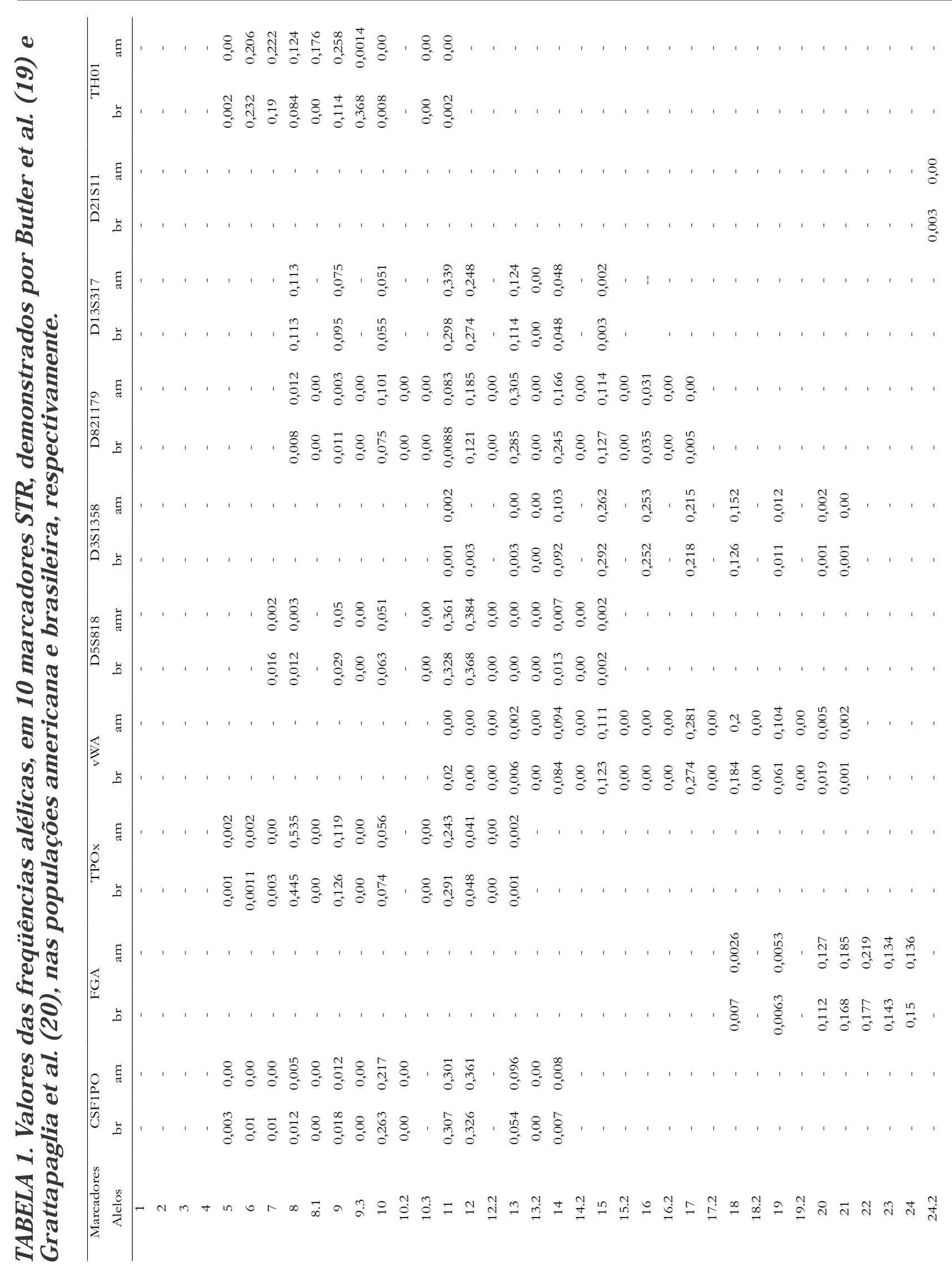




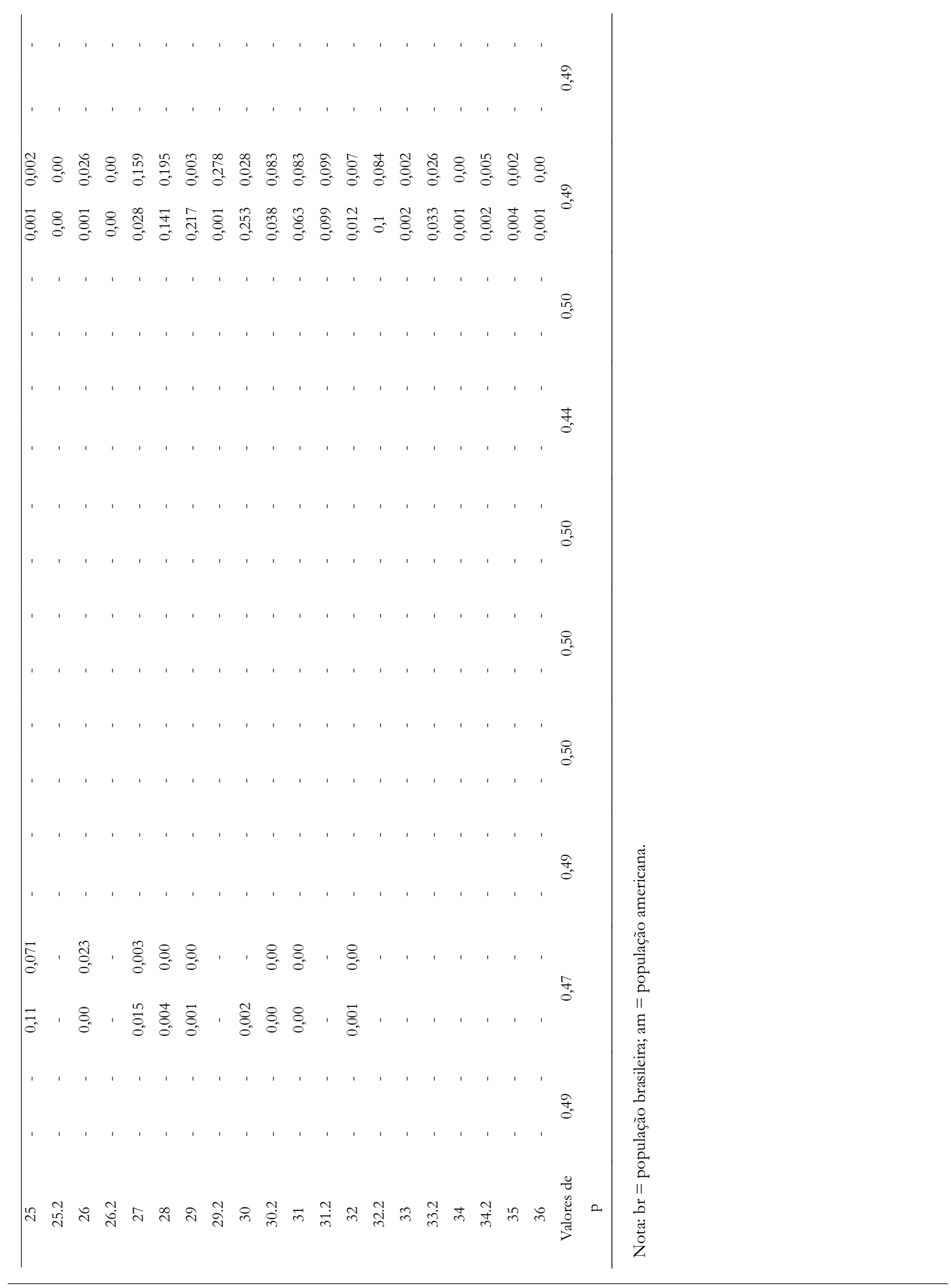




\section{Discussão e Conclusão}

Apesar da miscigenação brasileira e da não existência de raças, do ponto de vista genético, uma vez que não houve diversificação suficiente entre os vários grupos geográficos, as freqüências alélicas dos dez marcadores analisados não foram distintas entre as populações brasileira e dos Estados Unidos da América. Tal evidência indica a possibilidade de se utilizar bancos de dados norteamericanos em análises de DNA de populações brasileiras. Desta forma, caso existam marcadores genéticos que são específicos para um certo grupo étnico e são geograficamente restritos, a sua presença nas populações das quais putativamente são derivados pode fornecer pistas sobre a sua origem (22).

De acordo com Pena (7), polimorfismos em autossomos (cromossomos não-sexuais) são ótimos marcadores de individualidade. Como todos nós temos nos núcleos das nossas células duas cópias de cada autossomo e estas cópias de cada par trocam genes a cada geração, as combinações são efêmeras, impedindo que duas pessoas tenham o mesmo genoma. Por causa da recombinação, cada um dos nossos cromossomos autossômicos tem segmentos herdados de praticamente todos nossos antepassados.

De acordo com Santos e Bonatto (23), o Brasil é conhecido pelos antropólogos (24) como uma nação altamente diversa em etnias, com um nível acentuado de miscigenação, em que definições de coloração de pele e afinidade racial são extremamente ambíguas e variáveis. Isso pode ser até mesmo observado nas avaliações do censo pelo IBGE, em que em uma mesma família, os filhos podem pertencer a distintas categorias predefinidas: negro, pardo, branco, amarelo e indígena. Todavia, de acordo com marcadores autossômicos biparientais e marcadores uniparientais (cromossomo Y e DNA mitocondrial) o processo de miscigenação, presente no país desde os tempos da colonização permanece marcante em nossos genomas independentemente da aparência externa.

A espécie humana possui enorme variabilidade aparente o que permite discriminar os indivíduos de distintas partes do mundo (25). Tais diferenças são refletidas pelas migrações recentes, ou seja, nos últimos 100 mil anos, quando os homens deixaram a África e foram ocupando distin- tas regiões do globo, com clima, relevo, umidade, fontes de alimento, altamente diversificados. Isso fixou variações adaptativas sutis entre povos, tais como a pigmentação da pele com mais melanina, que confere proteção à radiação solar, ou com menos melanina, que permite a síntese de mais vitamina $\mathrm{D}$ na pele em situações de pouca iluminação solar (23). Entretanto, com o avanço do projeto genoma humano e a descrição de muitas variações de seqüências, além da obtenção de bancos de dados de freqüências alélicas, baseados em marcadores neutros como os STR, foi verificado que a espécie de Homo sapiens possui uma variabilidade, apesar de aparentemente enorme, muito menor do que outras espécies, como os grandes símios. Isto indica que o homem moderno surgiu em um tempo mais recente do que os demais, tanto que pouca variabilidade tem sido acumulada, assim como menores divergências genética e biológica entre as populações, em relação aos grandes símios (26).

Desta forma, este trabalho corrobora com os autores citados anteriormente, indicando que apesar da ausência de variabilidade entre as duas populações estudadas, a combinação destes dez marcadores vem a ser um valioso instrumento, que pode ser utilizado tanto para identificação individual, como testes de paternidade, identificação criminalística e mapeamento genético.

\section{Referências}

1. Matioli SR, Otto PA, Marroig G. Processos evolutivos 2000: genética de populações. [on line] 2000. Disponível em: http:// dreyfus.ib.usp.br/bio212 .

2. Beiguelman B. Dinâmica dos genes nas famílias e nas populações. 2 ed. Ribeirão Preto (Brasil): Sociedade Brasileira de Genética; 1994.

3. Castilho R. Genética de populações: noções básicas de aplicação em aquacultura. [on line] 2006. Disponível em: http:// www.w3.ualg.pt $\sim$ rcastil $\backslash$ Livro\%20GB\%Can\%A1rias\%20 Rita\%Castilho.

4. Lobo RB. Introdução a genética de populações. [on line] 2006. Disponível em: http:// www.rge.fmrp.usp.br/cursos/med1/ popula.doc. 
5. Stark AE. The Hardy-Weinberg principle. Genetics and molecular biology 2005; 38(3): 485-485.

6. Beeble T, Roule G. An introduction to molecular ecology. New York (EUA): Oxford University; 2004.

7. Pena SD. E que diabos vem a ser deriva genética? Ciência Hoje On Line [on line] 2006. Disponível em: http://cienciahoje.uol.com.br/4203.

8. Ferreira ME, Grattapaglia D. Introducción al uso de marcadores moleculares em el analisis genético. Brasi1lia (Brasil): EMBRAPA-CENARGEN; 1998.

9. Talhari DT. Avaliação da distância genética entre raças de bovinos sua correlação com heterozigose e desempenho. [Tese] São Carlos: Universidade Federal de São Carlos; 2003.

10. Goldstein, DB; Schlötterer, C. Microsatellites: evolution and applications. New York (EUA): Oxford University; 2001.

11. Jarne P, Lagoda PJL. Microsatellites, form molecules to populations and back. TREE 1996; 11(10):424429.

12. Moreira HW, Santana RK, Mattos LC, Ruiz MA. Avaliação do transplante de medula óssea alogênico por meio do estudo de regiões de repetições seqüenciais do genoma humano (VNTRs e STRs). Revista brasileira de hematologia e hemoterapia 2004; 26(2):109-113.

13. Shin SH, Yu JS, Park SW, Min GS, Chung KW. Genetic analysis of 18 linked short tandem repeat markers in Korean population. Forensic Science International 2005; 147:35-41.

14. Silva DA, Góes ACS, Carvalho JJ, Carvalho EF. DNA typing from vaginal smear slides in suspected rape cases. São Paulo Medical Journal 2004; 122(2):70-72.

15. Gusmão L, González-Neira A, Sanchez-Díz P, Lareu MV, Amorin A, Carracedo A. Alternative primers for DYS391 typing: advantages of their application to forensic genetics. Forensic Science International 2000; 112:49-57.

16. Gill P, Brenner C, Brinkmann B, Budowle B, Carracedo A, Jobling MA et al. DNA commission for the International Society of Forensic Genetics: recommendations on forensic analysis using Ychromosome STRs. Forensic Science International 2001; 124: 5-10.
17. Conselho Nacional de Pesquisa. Comitê sobre Tecnologia do DNA como Prova Forense. A avaliação do DNA como prova forense. Ribeirão Preto: FUNPEC-RP; 2001.

18. Leclair B, Frégeau CJ, Bowen KL, Fourney RM. Systematic analysis of stutter percentages and allele peak area ratios at heterozygous STR loci for forensic casework and database samples. Journal of Forensic Science 2004; 49(5):968-980.

19. Butler JM, Schoske R, Vallone PM, Redman JW, Kline MC. Allele frequencies for 15 autosomal STR loci on US Caucasian, African American and Hispanic populations. Journal of Forensic Sciences 2003; 48(4).

20. Grattapaglia D, Schmidt AB, Costa e Silva C, Stringher C, Fernandes AP, Ferreira ME. Brazzilian population database for the 13 loci of the AmpFlSTR ${ }^{\circledR}$ Prfiler Plus TM and Cofiler TM multiplex kits. Forensic Science International 2001; 118:91-94.

21. Ayres M, Ayres-Jr M. BioEstat: aplicações estatísticas nas áreas das ciências bio-médicas. Belém, Pará (Brasil): 2003.

22. Bonatto SL, Salzano FM. A single and early migration study for the peopling of the Americas supported by mithocondrial DNA sequence data. Proceedings of the National Academy of Sciences USA 1997; 94:1866-1871.

23. Santos FR, Bonatto SL. Genética de Populações Humanas. In: Mir, L(org.). Genômica. São Paulo (Brasil): Atheneu; 2004. p.17 - 37.

24. Kottak CP. Anthropology: the exploration of human diversity. 7. ed. New York (EUA): McGrawHill; 1997.

25. Bamshad MJ, Wooding S, Watkins WS, Ostler CT, Batzer MA, Jorde LB. Human population genetic structure and inference of group membership. American Journal of Human Genetics 2003; 72:578-589.

26. Kaessman H, Paabo S. The genetical history of humans and the great apes. Journal of International Medicine 2002; 251:1-18.

Recebido em / Received: January 9, 2006. Aceito em / Accepted: February 14, 2006. 